\title{
Changes in COVID-19-Associated Deaths During a Year Among Blacks and Hispanics Compared to Whites in the State of Connecticut
}

\author{
Cato T. Laurencin ${ }^{1,2,3,4,5,6,7} \cdot$ Z. Helen $\mathrm{Wu}^{1,8} \cdot$ James J. Grady ${ }^{1,9} \cdot$ Rong $\mathrm{Wu}^{1} \cdot$ Joanne M. Walker ${ }^{1,2}$
}

Received: 11 June 2021 / Revised: 11 August 2021 / Accepted: 1 September 2021 / Published online: 28 September 2021

○ W. Montague Cobb-NMA Health Institute 2021

\begin{abstract}
Background With recent COVID-19 vaccination rates relatively high in the USA, the USA still maintains the most documented cases globally,[1] even though COVID-19 cases, hospitalization, and mortality have been declining. However, the health burden has been largely felt in communities involving racial and ethnic minorities. Thus, in order to provide a clearer picture of what is happening in Black, Indigenous, and people of color communities, we examined the racial/ethnic differences of monthly COVID-19 deaths in Connecticut.

Methods This is an epidemiological study analyzing mortality data from March 1, 2020, to February 28, 2021, obtained from the Connecticut State Department of Public Health. The data include cause of death (COVID-19 death identified by ICD-10 code U071), race/ethnicity (non-Hispanic White (White), non-Hispanic Black (Black), and Hispanic), sex, and age. Both crude and age-adjusted rates were reported by racial/ethnic groups. To compare age-adjusted rates between racial groups, with estimated age-adjusted death counts as outcomes, between-racial group rate ratios, $95 \%$ confidence intervals, and $p$ values significant at $<0.05$ were derived from the Poisson regression model.

Results From March 2020 to May 2020 (wave 1) of COVID-19 cases, the COVID-19-related mortality rates were the highest for all three race groups (Whites, Blacks, and Hispanics) with statistical group differences $(p<0.05)$. Blacks had the highest rates of deaths followed by Hispanics and then Whites. Further, more Whites died in a nursing home when compared to Blacks and Hispanics. From June 2010 to October 2020 (wave 2), COVID-19 mortality declined significantly for all three race groups with no statistical differences between groups. COVID-19 deaths in nursing homes declined for all three racial/ ethnic groups. From November 2020 to February 2021 (wave 3), COVID-19 mortality rates were significantly higher compared to wave 2 but lower than wave 1 for all three race groups. The mortality rates for Blacks and Hispanics were higher than Whites. Hispanics had the highest rates of deaths, followed by Blacks, and then Whites $(p<0.05)$. Whites showed the lowest mortality rates among all three racial/ethnic groups.

Conclusions In summary, COVID-19 health disparities among Black and Hispanic populations were evident in this study. Blacks and Hispanics had significantly higher mortality rates when compared to Whites. Blacks had the highest mortality rates during wave 1 , and in wave 3, Hispanics has the highest mortality rates. Our data are important because they show monthly COVID-19 deaths data by race. Data reported this way gives a better and more accurate understanding of what is really happening in Black, Indigenous, and people of color populations.
\end{abstract}

Keywords COVID-19 $\cdot$ Monthly $\cdot$ Data $\cdot$ Coronavirus $\cdot$ Racial $\cdot$ Ethnic $\cdot$ Disparity $\cdot$ Community $\cdot$ Death $\cdot$ Hispanic $\cdot$ Black

\section{Background}

Coronavirus disease 2019 (COVID-19) and its variants continue rampaging different parts of the world unprecedentedly. With recent COVID-19 vaccination rates relatively

Cato T. Laurencin

laurencin@uchc.edu

Extended author information available on the last page of the article high in the USA, the USA still maintains the most documented cases globally,[1] even though COVID-19 cases, hospitalization and mortality have been declining (https:// www.washingtonpost.com/health/interactive/2021/covidrates-unvaccinated-people/). However, health burdens are largely felt in communities of racial/ethnic minorities.[2, 3] Black communities are marred with health and economic challenges, and we were among the first to report that these communities are strained further in the time of crisis.[4] 
The disproportionate impact of the severe acute respiratory syndrome coronavirus 2 (SARS-CoV-2) on Blacks is widely reported and reflected in higher mortality rates.[5]

According to the most recent mortality reported as of April 7, 2021 (Fig. 1) (https://portal.ct.gov/-/media/Coron avirus/CTDPHCOVID19summary4082021.pdf), the ageadjusted accumulative COVID-19-related death rates were found the highest among Blacks (278 deaths per 100,000 populations), the second highest among Hispanics (255 deaths per 100,000 populations), and then among Whites (128 deaths per 100,000 populations). COVID-19 mortality rates for Blacks and Hispanics was two times greater than Whites from March 2020 to April 2021. Thus, analyzing COVID-19-related death monthly data over a period of 12 months from March 2020 to February 2021 is more accurate than cumulative data. Looking at monthly data will give a clearer picture of what is happening in minority communities. This work examines the racial/ethnic differences of monthly COVID-19 deaths in Connecticut.

\section{Design}

This is an epidemiological study analyzing mortality data from March 1, 2020, to February 28, 2021, that includes COVID-19-positive cases from March to May 2020 (wave 1), June to October 2020 (wave 2), and November 2020 to February 2021 (wave 3) (wave 4 starting March 2021). Data were obtained from the Connecticut State Department of Public Health. The data include cause of death (COVID19 death identified by ICD-10 code U071), race/ethnicity (non-Hispanic White (White), non-Hispanic Black (Black), Hispanic), sex, and age. Other racial/ethnic groups were not included in the analysis due to low numbers of COVID-19 deaths in these categories. Crude fatality rates per year per 100,000 were calculated using COVID-19 related deaths from the CT public dataset (https://portal.ct.gov/DPH/ Health-Information-Systems- Reporting/File-Transfer-Page/ Connecticut-DPH-File-Transfer-Page) along with the 2019 CT population statistics (https://portal.ct.gov/DPH/HealthInformation-Systems--Reporting/Population/Annual-State-County-Population-with-Demographics) for the per year base population estimates for each age group and racial/ ethnic group.

Age-adjusted rates were calculated using the 2019 Connecticut DPH population statistics and 2000 US Standard Million populations (https://seer.cancer.gov/seerstat/tutor ials/aarates/step3.html). To compare age-adjusted rates between racial groups, estimated age-adjusted death counts in each racial group were obtained by multiplying ageadjusted rate and racial population. Poisson regression was then performed with estimated age-adjusted death count as the outcome as the offset variable, race as an explanatory variable, and the population size of each racial group. The between-racial group rate ratios, $95 \%$ confidence intervals, and $p$ values significant at $<0.05$ were derived from the Poisson regression model.

\section{Results}

\section{Monthly COVID-19 Deaths from March 2020 to February 2021 by Race/Ethnicity}

A total of 7531 COVID-19-related deaths occurred in Connecticut from March 1, 2020, to February 28, 2021; this includes 5773 Whites (76.7\%), 979 Blacks (13.0\%), and 779 Hispanics (10.3\%). For all racial/ethnic groups, the highest
Fig. 1 Rate of COVID19-associated deaths by race/ ethnicity, with and without age adjustment as of April 7, 2021. (https://portal.ct.gov/-/media/ Coronavirus/CTDPHCOVID 19summary4082021.pdf)

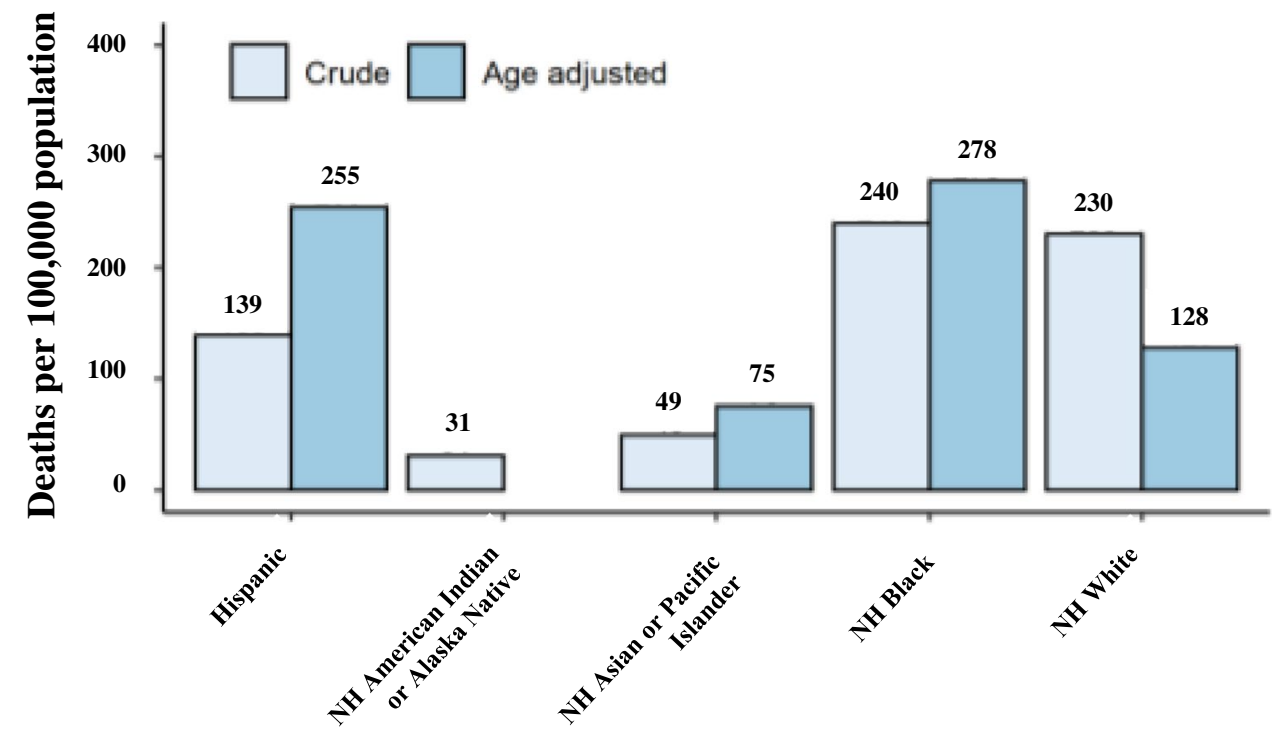


age-adjusted death rates occurred in April 2020, and the lowest were in August 2020.

The COVID-19 mortality rates were the highest during the first COVID-19 wave (March-May 2020 (wave $1)$ ). The highest age-adjusted mortality rate was seen in Blacks (188.1, $n=643$ ), followed by Hispanics (117.5, $n=387)$, and then Whites $(67.2, n=2997)$, with the highest rate of deaths for all races in the month of April 2020 (Black 111.5, $n=382$; Hispanic 72.9, $n=235$; and Whites $40.5, n=1782$ ) (Fig. 2, Table 1). During the 2nd COVID19 wave, June to October 2020, the mortality rates were observed to be lower than in the first wave but still the highest in the Black population (Black 19, $n=67$; Hispanic 17.8, $n=61$; and Whites 9.9, $n=436$ ). During the second wave, the highest death rate for all populations (Black, Hispanic, and White) was observed in the month of June 2020. During the third wave from November 2020 to February 2021 , the rates were increasing for all three race groups, with the highest rates in Hispanics $(95.4, n=331$ ), followed by Blacks $(77.2, n=269)$, and then Whites (54, $n=2,341$ ).

Finally, when comparing the COVID-19-related mortality rates in the peak month, April 2020, the percent mortality rate reduction in all three racial/ethnic groups
Fig. 2 Age-adjusted COVID19-related deaths per 100,000 population by racial/ethnic status in Connecticut: March 2020 to February 2021

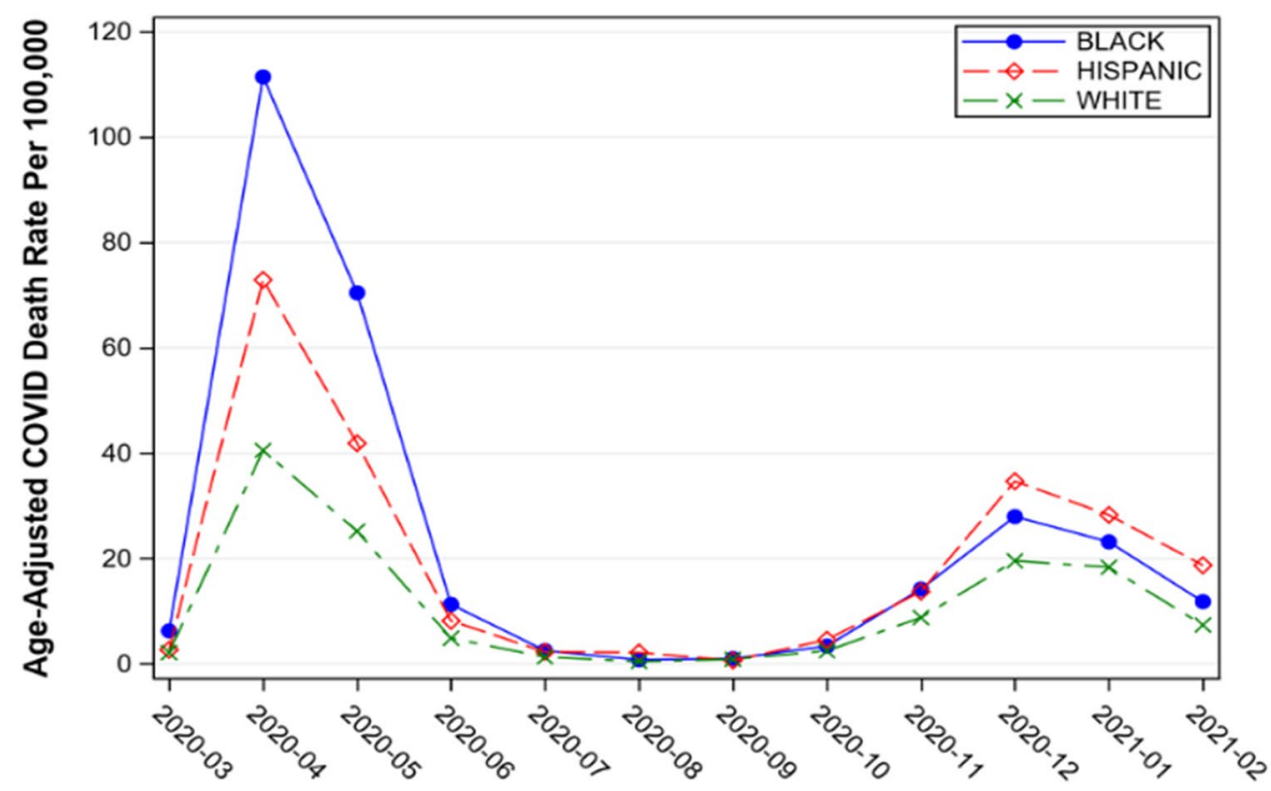

\begin{tabular}{|c|l|c|c|c|c|c|c|c|c|c|}
\hline \multicolumn{2}{|c|}{} & \multicolumn{3}{c}{ BLACK } & \multicolumn{3}{c|}{ HISPANIC } & \multicolumn{3}{c|}{ WHITE } \\
\hline $\begin{array}{c}\text { Covid- } \\
19 \\
\text { Wave }\end{array}$ & Month & Rate & $\mathbf{n}$ & $\begin{array}{c}\% \text { rate } \\
\text { reduction }\end{array}$ & Rate & n & $\begin{array}{c}\% \text { rate } \\
\text { reduction }\end{array}$ & Rate & n & $\begin{array}{c}\% \text { rate } \\
\text { reduction }\end{array}$ \\
\hline $\mathbf{1}$ & $2020-03$ & 6.2 & 20 & - & 2.7 & 10 & - & 2.1 & 91 & - \\
\hline $\mathbf{1}$ & $2020-04$ & 111.5 & 382 & Ref & 72.9 & 235 & Ref & 40.5 & 1783 & Ref \\
\hline $\mathbf{1}$ & $2020-05$ & 70.4 & 241 & $37 \%$ & 41.9 & 142 & $43 \%$ & 25.2 & 1122 & $38 \%$ \\
\hline $\mathbf{2}$ & $2020-06$ & 11.3 & 39 & $90 \%$ & 8.2 & 27 & $89 \%$ & 4.8 & 211 & $88 \%$ \\
\hline $\mathbf{2}$ & $2020-07$ & 2.5 & 10 & $98 \%$ & 2.3 & 9 & $97 \%$ & 1.3 & 58 & $97 \%$ \\
\hline $\mathbf{2}$ & $2020-08$ & 0.8 & 3 & $99 \%$ & 2.1 & 7 & $97 \%$ & 0.4 & 19 & $99 \%$ \\
\hline $\mathbf{2}$ & $2020-09$ & 1.0 & 4 & $99 \%$ & 0.6 & 2 & $99 \%$ & 0.9 & 36 & $98 \%$ \\
\hline $\mathbf{2}$ & $2020-10$ & 3.4 & 11 & $97 \%$ & 4.6 & 16 & $94 \%$ & 2.5 & 112 & $94 \%$ \\
\hline $\mathbf{3}$ & $2020-11$ & 14.2 & 50 & $87 \%$ & 13.7 & 52 & $81 \%$ & 8.8 & 388 & $78 \%$ \\
\hline $\mathbf{3}$ & $2020-12$ & 28.0 & 95 & $75 \%$ & 34.7 & 120 & $52 \%$ & 19.5 & 846 & $55 \%$ \\
\hline $\mathbf{3}$ & $2021-01$ & 23.2 & 82 & $79 \%$ & 28.3 & 95 & $61 \%$ & 18.3 & 796 & $55 \%$ \\
\hline $\mathbf{3}$ & $2021-02$ & 11.8 & 42 & $89 \%$ & 18.7 & 64 & $74 \%$ & 7.4 & 311 & $82 \%$ \\
\hline
\end{tabular}

The color is desginated to each wave of the Covid-19 pandemic
Table 1 Age-adjusted rates and number of COVID-19 deaths by race in Connecticut per 100,000 populations 
ranged from about 90 to $99 \%$ during wave 2 and between 50 and $90 \%$ during the wave 3 .

\section{Rate Ratios of Death Rates Comparing Blacks, Hispanics, and Whites}

\section{Blacks vs. Whites}

The COVID-19 rate ratio of mortality rates when comparing Blacks vs. Whites generally declined from March 2020 to February 2021 in Connecticut (Table 2). During the first wave, from March to May 2020, mortality rates for Blacks was about 2 times significantly higher than those for Whites $(p<0.0001)$. During the second wave, June to October 2020, the rate ratios were not statistically different from July to October for Blacks when comparing Whites except for June $2020(p<0.0001)$. During the third wave from November 2020 to February 2021, the age-adjusted COVID-19 mortality rates for Blacks were statistically higher than what was observed in Whites ( $p<0.05$, ranging $p<0.001$ to 0.04 ).

\section{Hispanics vs. Whites}

The COVID-19 rate ratio of mortality rates comparing Hispanics and Whites showed similar patterns to what was observed in Blacks in Connecticut. In the first wave, Hispanics had a significantly higher ratio of mortality rates in April and May 2020 than whites $(p<0.0001)$. During the second wave, from June to October, there was no significant difference in mortality ratio of Hispanics compared to White. On the other hand, during the third wave, the Hispanics had a significantly higher mortality ratio when compared to Whites in December 2020, January, and February $2021(p<0.0001)$. In November, there was no significant difference between the two races (Table 2).

\section{Blacks vs. Hispanics}

In Connecticut, the mortality ratio rates between Blacks and Hispanics were statistically higher among Blacks during the first wave, (March 2020, $p<0.01$; April and May $2020, p<0.0001)$. During the second COVID-19 wave (June to October 2020), there was no significant difference in mortality ratio rates. However, during the third wave, in February 2021, Blacks were 63\% higher in COVID-19 mortality rate than Hispanics $(p=0.01)$. From November 2020 to January 2021, there were no statistical differences in mortality rates between Blacks and Hispanics (Table 2).

\section{Absolute Differences of Death Rates Blacks and Hispanics Compared with Whites}

In Connecticut, the differences of mortality rate in Blacks and Hispanics when compared to Whites (Fig. 3) were observed to be the highest in April and May 2020. For Blacks, there were 70 more deaths per 100,000 and about 30 deaths per 100,000 for Hispanics when compared to Whites. From July to October 2020, there is a similar trend in mortality rates for Black and Hispanics, and no difference observed when compared to Whites. In December 2020, the deaths slightly increased in Blacks and Hispanics; Blacks had about 15 deaths when compared to Whites and Hispanics about 9 deaths (Fig. 3).
Table 2 Ratio of age-adjusted rates of deaths in Connecticut per 100,000 populations for Blacks and Hispanics compared to Whites

\begin{tabular}{|c|c|c|c|c|c|c|c|c|c|c|c|c|c|}
\hline \multirow{3}{*}{$\begin{array}{c}\text { Covid- } \\
19 \\
\text { Wave } \\
1 \\
\end{array}$} & \multirow{3}{*}{$\begin{array}{l}\text { Month } \\
2020-03\end{array}$} & \multicolumn{4}{|c|}{ Black/White } & \multicolumn{4}{|c|}{ Hispanic/White } & \multicolumn{4}{|c|}{ Black/Hispanic } \\
\hline & & \multirow{2}{*}{$\begin{array}{l}\text { Ratio } \\
2.93 \\
\end{array}$} & \multicolumn{2}{|c|}{$95 \% \mathrm{CL}$} & \multirow{2}{*}{$\begin{array}{c}\mathbf{P} \\
\text { Value }\end{array}$} & \multirow{2}{*}{$\begin{array}{l}\text { Ratio } \\
1.25\end{array}$} & \multicolumn{2}{|c|}{$95 \% \mathrm{CL}$} & \multirow{2}{*}{$\begin{array}{c}\begin{array}{c}\mathbf{P} \\
\text { value }\end{array} \\
0.44\end{array}$} & \multirow{2}{*}{$\begin{array}{l}\text { Ratio } \\
2.34 \\
\end{array}$} & \multicolumn{2}{|c|}{$95 \% \mathrm{CL}$} & \multirow{2}{*}{$\begin{array}{c}\begin{array}{c}\mathbf{P} \\
\text { value }\end{array} \\
0.01 \\
\end{array}$} \\
\hline & & & 1.81 & 4.74 & & & 0.71 & 2.19 & & & 1.25 & 4.40 & \\
\hline 1 & 2020-04 & 2.75 & 2.46 & 3.08 & $<.0001$ & 1.80 & 1.61 & 2.01 & $<.0001$ & 1.53 & 1.34 & 1.75 & $<.0001$ \\
\hline 1 & 2020-05 & 2.80 & 2.42 & 3.22 & $<.0001$ & 1.66 & 1.44 & 1.93 & $<.0001$ & 1.68 & 1.42 & 1.99 & $<.0001$ \\
\hline 2 & $2020-06$ & 2.33 & 1.65 & 3.30 & $<.0001$ & 1.69 & 1.21 & 2.36 & 0.00 & 1.38 & 0.92 & 2.08 & 0.12 \\
\hline 2 & $2020-07$ & 1.92 & 0.93 & 3.94 & 0.08 & 1.74 & 0.92 & 3.29 & 0.09 & 1.10 & 0.48 & 2.51 & 0.82 \\
\hline 2 & $2020-08$ & 1.77 & 0.48 & 6.48 & 0.39 & 5.03 & 2.21 & 11.46 & 0.00 & 0.35 & 0.10 & 1.25 & 0.11 \\
\hline 2 & 2020-09 & 1.16 & 0.39 & 3.43 & 0.79 & 0.74 & 0.25 & 2.21 & 0.59 & 1.57 & 0.38 & 6.46 & 0.53 \\
\hline 2 & $2020-10$ & 1.37 & 0.75 & 2.48 & 0.30 & 1.85 & 1.18 & 2.91 & 0.01 & 0.74 & 0.38 & 1.43 & 0.37 \\
\hline 3 & 2020-11 & 1.62 & 1.20 & 2.17 & $<0.001$ & 1.56 & 1.21 & 2.01 & 0.00 & 1.04 & 0.74 & 1.46 & 0.84 \\
\hline 3 & $2020-12$ & 1.43 & 1.16 & 1.76 & $<0.001$ & 1.77 & 1.51 & 2.09 & $<.0001$ & 0.81 & 0.64 & 1.02 & 0.07 \\
\hline 3 & 2021-01 & 1.26 & 1.01 & 1.58 & 0.04 & 1.54 & 1.29 & 1.84 & $<.0001$ & 0.82 & 0.63 & 1.06 & 0.12 \\
\hline 3 & 2021-02 & 1.60 & 1.16 & 2.22 & $<0.001$ & 2.54 & 2.01 & 3.22 & $<.0001$ & 0.63 & 0.45 & 0.89 & 0.01 \\
\hline
\end{tabular}

The color is desginated to each wave of the Covid-19 pandemic 
Fig. 3 Difference of ageadjusted rates of deaths in Connecticut per 100,000 populations for Blacks and Hispanics compared to Whites

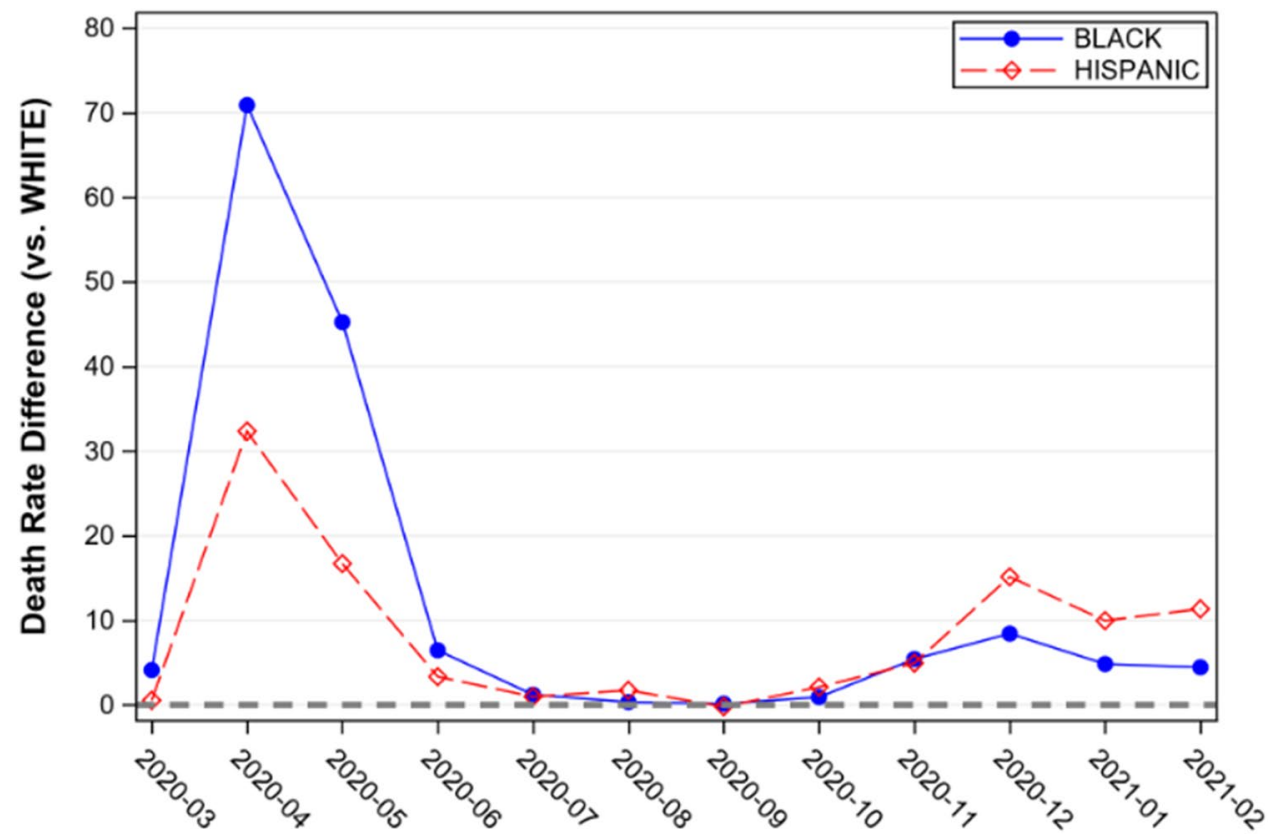

\section{Places of Deaths Attributed to COVID-19 by Racial/ Ethnic Status}

Whites reported the highest mortality rates in nursing homes, about $50 \%$, with a sharp decline from July to September 2020 in Connecticut (Fig. 4). In July 2020, the COVID-19 deaths for Hispanics in a nursing home were about $45 \%$ and for Blacks about $40 \%$, with a sharp decline from August to September 2020. In December 2020, the mortality rate of Whites is a nursing home was about $40 \%, 20 \%$ for Blacks, and about 5\% for Hispanics. Particularly around Feb 2021, the mortality rates in nursing homes began to converge for all race groups (Fig. 4).

\section{Conclusion}

The coronavirus disease has affected and devastated the world, with unprecedented projected mortality and economic devastation. Racial and ethnic minorities are at a disadvantage, and data from Connecticut show that Black Americans are dying from the virus at twice the rate of
Fig. 4 Percent of associated COVID-19 deaths in a nursing home by race

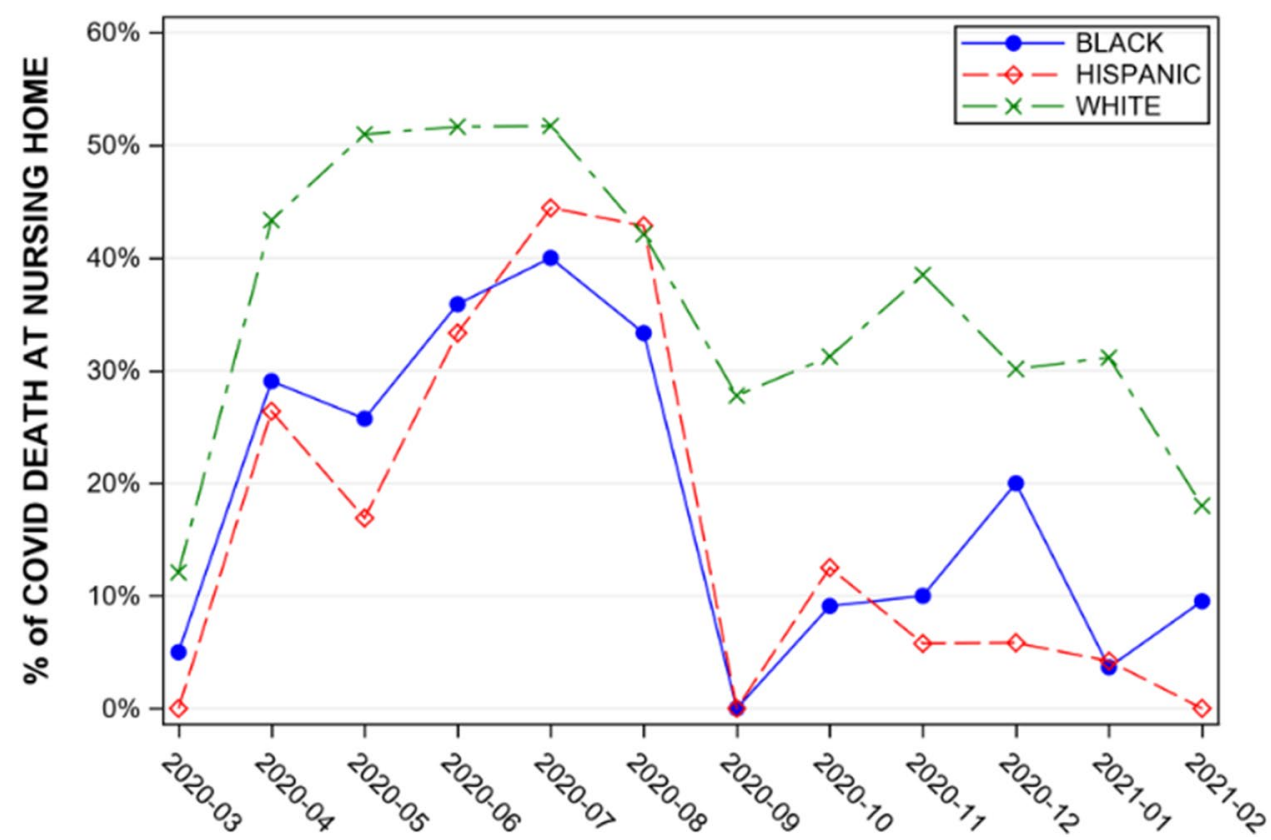


Whites. Black Americans are disproportionately affected due to poverty, mass incarceration, infant mortality, limited health care access, and health-related conditions including heart disease, diabetes, stroke, kidney disease, respiratory illness, and human immunodeficiency virus (HIV) and continued racism and discrimination. The lack of reported and accessible data on the racial and ethnic composition of those infected may result in historically marginalized groups shouldering an even higher burden of disease and disproportionately bearing higher social impact.

Current data on the coronavirus and its effect on different populations is aggregated from the entire population and does not reflect the realities of Black and Hispanic populations. Blacks maintain greater disease burdens due to higher poverty rates, limited health care access, and increased jobs in the service industries. Without data by race and ethnicity, Black and Latino citizens are at an increased risk when states begin to "open-up." A review by Donald J. Alcendor in the Journal of Clinical Medicine reported that out of 131 African American counties, the death rate per 100,000 was 6.3, which is six times higher than predominantly Non-Hispanic White counties[6]. This data clearly shows the presence of racial and ethnic disparities in minority groups.

Our study focused analyzing COVID-19-related death data monthly over a period of 12 months from March 2020 to February 2021 by race to more accurately determine what is happening in minority communities in Connecticut. From our data, we found that the COVID-19 mortality rates were the highest for all three-race groups (Whites, Blacks, and Hispanics) during the first wave (March to May 2020). The mortality by rate ratios and absolute differences between Blacks and Whites and between Blacks and Hispanics were statistically significant. A similar pattern was observed when comparing Hispanics to Whites. Further, more Whites died in a nursing home when compared to Blacks and Hispanics.

During the second wave (June to October 2020), the COVID-19 mortality declined significantly for all three race groups in Connecticut. There were no statistical differences in rate ratios and absolute differences between Blacks, Hispanics, and Whites during the second wave. However in August 2020, there was a fivefold increase in COVID19 mortality in Hispanics when compared to Whites. The absolute difference of rates for Hispanics (2.1 per 100,000 populations) and for Whites ( 0.4 per 100,000 populations) was not statistically different. Thus, this rate ratio was due to the comparison of low mortality rates; hence, this is an interpretation of the data collected. In general, for all three racial/ethnic groups, substantial rate reductions were observed (90-99\%) when comparing to the peak COVID19-associated mortality rate. During this time, COVID-19 deaths in nursing home declined for all three racial/ethnic groups.
From November 2020 to February 2021 (wave 3), the COVID-19 mortality rates were significantly on the rise compared to wave 2 but lower than wave 1 for all three-race groups in Connecticut. However, the mortality rates were the highest among Hispanics, compared to Whites and Blacks. Whites showed the lowest mortality rates among all three racial/ethnic groups. In general, for all three racial/ethnic groups, comparing to the peak COVID-19-associated mortality rate, more variable rate reductions $(50-90 \%)$ but less than what observed in wave 2 were reported. Moreover, the differences between Blacks and Hispanics in wave 1 were substantially reduced even though not eliminated in wave 3 . Thus, further studies will be suggested to explore the risk and beneficial factors of such changes.

In summary, COVID-19 health disparities among the Black and Hispanic populations in Connecticut was evident in this study. Blacks and Hispanics had significantly higher mortality rates when compared to Whites. Blacks had the highest mortality rates in wave 1 , and now in wave 3, Hispanics have been leading the mortality rates. Our study mirrors data that has been already presented. For example, a study by Mackey et al. stated that the CDC's National Center for Health Statistics (NCHS) reported 15\% excess deaths among the African American population compared to White and for Hispanics approximately $21 \%$ excess deaths. Data from APM Research Lab reported that the risk of mortality rate for African Americans and Hispanics was 3.2 times higher than compared to White populations[7]; many other studies confirm these findings[8-12]. However, there are limitations of our study; for example, our current study did not include the race/ethnicity and sex interaction on COVID19 mortalities or how urban, suburban, and rural residential statue may have differential effect across these racial/ethnic groups particularly in some states with larger populations. Besides these limitation, future studies are suggested to understand the sources of higher-than-expected White mortality in nursing homes by exploring geographic variation, racial composition, and per-center mortality as well as to understand the COVID-19 mortality patterns among other racial/ethnic groups. In summary, our data is important because it shows monthly COVID-19 death data by race. Data reported that this gives a better, more accurate, and timely understanding of COVID-19 mortalities in minority populations.

Funding The authors would like to acknowledge support from the National Institutes of Health (NIH): NIH BUILD (TL4GM118971) for funding his work (C.T.L.).

\section{Declarations}

Ethics Approval This article does not contain any studies with human participants or animals performed by any of the authors. 
Informed Consent Not applicable.

Conflict of Interest The authors declare no competing interests.

\section{References}

1. Johns Hopkins University Coronavirus Resource Center. Covid19 Dashboard. https://coronavirus.jhu.edu/map.html. Accessed 26 October 2020

2. Laurencin CT, Walker JM. A pandemic on a pandemic: racism and COVID-19 in Blacks. Cell Syst. 2020;11(1):9-10. https://doi.org/ 10.1016/j.cels.2020.07.002.

3. Poteat T, Millett GA, Nelson LRE, Beyrer C. Understanding COVID-19 risks and vulnerabilities among black communities in America: the lethal force of syndemics. Ann Epidemiol. 2020;47:1-3. https://doi.org/10.1016/j.annepidem.2020.05.004.

4. Laurencin CT, McClinton A. The COVID-19 pandemic: a call to action to identify and address racial and ethnic disparities. J Racial Ethn Heal Disparities. 2020;7:398-402. https://doi.org/10.1007/ s40615-020-00756-0.

5. Gross CP, Essien UR, Pasha S, Gross JR, Wang S, Nunez-Smith M. Racial and ethnic disparities in population-level COVID-19 mortality. J Gen Intern Med. 2020;35:3097-9.

6. Alcendor DJ. Racial Disparities-Associated COVID-19 Mortality among minority populations in the US. J Clin Med. 2020;9(8):2442. https://doi.org/10.3390/jcm9082442.

7. Mackey K, Ayers CK, Kondo KK, Saha S, Advani SM, Young S, Spencer H, Rusek M, Anderson J, Veazie S, Smith M, Kansagara
D. Racial and ethnic disparities in COVID-19-related infections, hospitalizations, and deaths : a systematic review. Ann Intern Med. 2021;174(3):362-73. https://doi.org/10.7326/M20-6306.

8. Li AY, Hannah TC, Durbin JR, Dreher N, McAuley FM, Marayati NF, Spiera Z, Ali M, Gometz A, Kostman JT, Choudhri TF. Multivariate analysis of black race and environmental temperature on COVID-19 in the US. Am J Med Sci. 2020;360(4):348-56. https://doi.org/10.1016/j.amjms.2020.06.015.

9. Millett GA, Jones AT, Benkeser D, Baral S, Mercer L, Beyrer C, Honermann B, Lankiewicz E, Mena L, Crowley JS, Sherwood J, Sullivan PS. Assessing differential impacts of COVID-19 on black communities. Ann Epidemiol. 2020;47:37-44. https://doi.org/10. 1016/j.annepidem.2020.05.003.

10. Sehra ST, Fundin S, Lavery C, Baker JF. Differences in race and other state-level characteristics and associations with mortality from COVID-19 infection. J Med Virol. 2020;92(11):2406-8. https://doi.org/10.1002/jmv.26095.

11. Khazanchi R, Beiter ER, Gondi S, Beckman AL, Bilinski A, Ganguli I. County-Level Association of social vulnerability with COVID-19 cases and deaths in the USA. J Gen Intern Med. 2020;35(9):2784-7. https://doi.org/10.1007/s11606-020-05882-3.

12. Nayak A, Islam SJ, Mehta A, Ko YA, Patel SA, Goyal A, ..., Quyyumi AA. Impact of social vulnerability on COVID-19 incidence and outcomes in the United States. medRxiv. 2020

Publisher's Note Springer Nature remains neutral with regard to jurisdictional claims in published maps and institutional affiliations.

\section{Authors and Affiliations}

\section{Cato T. Laurencin ${ }^{1,2,3,4,5,6,7} \cdot$ Z. Helen $\mathrm{Wu}^{1,8}$. James J. Grady ${ }^{1,9} \cdot$ Rong $\mathrm{Wu}^{1} \cdot$ Joanne M. Walker ${ }^{1,2}$}

1 Connecticut Convergence Institute for Translation in Regenerative Engineering, University of Connecticut Health Center, UConn Health, 263 Farmington Avenue L7036, Farmington, CT 06030, USA

2 Department of Surgery, University of Connecticut School of Medicine, Farmington, CT 06030, USA

3 Raymond and Beverly Sackler Center for Biomedical, Biological, Physical and Engineering Sciences, Farmington, CT 06030, USA

4 Department of Orthopaedic Surgery, University of Connecticut Health Center, Farmington, CT 06030, USA
5 Department of Materials Science \& Engineering, University of Connecticut, Storrs, CT 06269, USA

6 Department of Biomedical Engineering, University of Connecticut, Storrs, CT 06269, USA

7 Department of Chemical \& Biomolecular Engineering, University of Connecticut, Storrs, CT 06269, USA

8 Department of Psychiatry, University of Connecticut Health Center, Farmington, CT 06030, USA

9 Department of Population Health Science, University of Connecticut Health Center, Farmington, CT 06030, USA 